\title{
The Importance of Fresh Frozen Section in Muscle Biopsy for Diagnostic Purposes
}

\author{
Rino Pattiata, ${ }^{1,2,3}$ Ikuya Nonaka ${ }^{3}$
}

\begin{abstract}
Abstrak
Penggunaan potong beku pada biopsi otot telah dilakukan pada berbagai institut sejak tiga puluh tahun yang lalu. Banyak kelainan neuromuskuler baru ditemukan sejak penggunaan potong beku, karena beberapa kelainan patologis otot hanya dapat ditemukan pada potong beku termasuk miopati mitokondrial dan berbagai miopati kongenital nonprogresif. Dengan ditemukannya distrofin dan dystrophin-associated glycoprotein (DAG) maka kelainan distrofi otot lebih dikenal. Dengan penggunaan distrofin dan DAG secara imunohistokimia, diagnosis distrofi otot dapat ditegakkan lebih akurat. Melihat kemajuan yang ada ini, maka sudah waktunya penggunaan teknik potong beku pada biopsi otot diterapkan di Indonesia.
\end{abstract}

\begin{abstract}
Fresh frozen sections has been applied on muscle biopsy for more than 30 years in many institutes, With this procedure, many new muscular disorders has been found because certain myopathic changes including mitochondrial myopathy, and various congenital myopathies can only be detected by using fresh frozen section. The discovery of dystrophin and dystrophin-associated glycoproteins (DAG) has provided the knowlegde for better understanding the pathogenesis of muscular dystrophy. By immunohistochemical studies of dystrophin and DAG, the diagnosis of muscular dystroiphy has become more accurate. Looking at this progress, it is time for Indonesia to introduce muscle histochemistry of fresh frozen muscle specimen for muscle biopsy.
\end{abstract}

Keywords: histochemistry, immunohistochemistry, muscular dystrophy, congenital myopathy.

Muscle biopsy is a diagnostic tool which provides us the knowledge to detect abnormalities in muscles. The pathological findings reflect the pathogenetic mechanism whether it is myopathic, neuropathic or both. In the last two decdes, we have seen a renewed and growing interest in muscles because of the application of new techniques, including histochemsitry, immunohistochemistry, electron microscopy, and molecular biology. Thus we have detected a number of new muscle disorders, and understood the underlying pathophysiology of muscle pathologies. Muscle biopsy is a relatively simple procedure. To interprete the

1. Department of Anatomic Pathology, Faculty of Medicine, University of Indonesia/Cipto Mangunkusumo National Central General Hospital, Jakarta, Indonesia

2. International Center of Medical Research, Genetic Divisions, Kobe University School of Medicine, Kobe, Japan

3. National Institute of Neuroscience, National Center of Neurology and Psychiatry, Kodaira, Japan biopsy specimen, histochemical methods are needed. In Irdonesia muscle biopsies were embedded in paraffin without histochemical treatment.

In this paper we will describe the technique of fixation and staining of muscle biopsy histochemically as well as immunohistochemically. and underline the pitfalls we must be aware of.

\section{MUSCLE BIOPSY AND THE STAINING}

Muscle biopsy is a relative simple procedure. However, one must make sure that the local anesthesia is given subcutaneously, and not intramuscularly. For children under 6 years, we may use sedatives or general anesthesia. We can biopsy any muscle, but mild to moderately affected muscles are the best. In severely affected muscles, the muscle tissue may be replaced by fat and fibrous tissue with no detectable traces of an underlying disease process. On the othe hand, a muscle without symptoms does not provide sufficient change. By experience, the biceps brachii muscle is the 
best site for biopsy, because 1) it is easy to reach the muscle tissue; 2) it contains abundant peripheral nerves and muscle spindles; 3 ) type 1,2A, and 2B fibers are distributed in a mosaic pattern; and 4) there is little fibrous interstitial tissue. ${ }^{1,2}$

The biopsy is done as follows: after cleaning with an antiseptic, the skin is infiltrated by local anesthesia. It is important not to infiltrate the muscle, because the local anesthetic agent is highly toxic to the muscles, thus inducing muscle fiber necrosis. A skin incision of about 3-4 $\mathrm{cm}$ is performed along the direction of the muscle fibers. After retraction of the skin, the fascia is incised to expose the muscle fascicles. Then a segment of the muscle is cut off by a pair of scissors. The fascia is sutured and the skin is closed.

The muscle specimen should be frozen as quickly as possible. According to our experience, we can delay it till 30 minutes. We do not use direct immersion in liquid nitrogen, because nitrogen gas bubbles surrounding the specimen will appear and retard the cooling process, thus causing artefacts. The specimen is placed on a piece of cork with tragacanth gum, fixed in isopentane, and cooled with liquid nitrogen.

If necessary, before fixing the specimen, a part of the muscle is fixed for electron microscopy.

The specimen is then ready to be stained. In our laboratory in Japan, we perform a battery of histochemical stainings including hematoxylin and eosin (H\&E), modified Gomori trichrome (MGT), reduced nicotinamide adenine dinucleotide reductase (NADHTR), succinic dehydrogenase (SDH), periodic acidSchiff (PAS), oil red O, adenosine triphosphatase (ATPase), non spesific esterase (NSE), acid phosphatase, alkaiine phosphatase, acetylcholine esterase, cytochrome C-oxydase (CCO), adenosine monophosphate (AMP) deaminase, phosphorylase, phosphofructokinase (PFK), menadione-linked alpha-glycerolphosphate dehydrogenase. ${ }^{2}$

$\mathrm{H} \& \mathrm{E}$ is the most important staining, because most of the pathological information can be traced by this staining. We can differentiate the fibers with $H \& E$ staining; type 1 fiber is stained darker than type 2. However, we need additional staining for further differentiation. With simple H\&E staining, we may overlook several abnormalities such as nemaline bodies, cytoplamic bodies, central core, which are commonly seen in congenital non-progressive myopathies. (Fig.1)

In mitochondrial myopathy, some important findings are red ragged fibers (RRF), strongly SDH blood vessels (SSV) and focal deficiency of cytochrome Coxydase activities. RRF is stained differently with

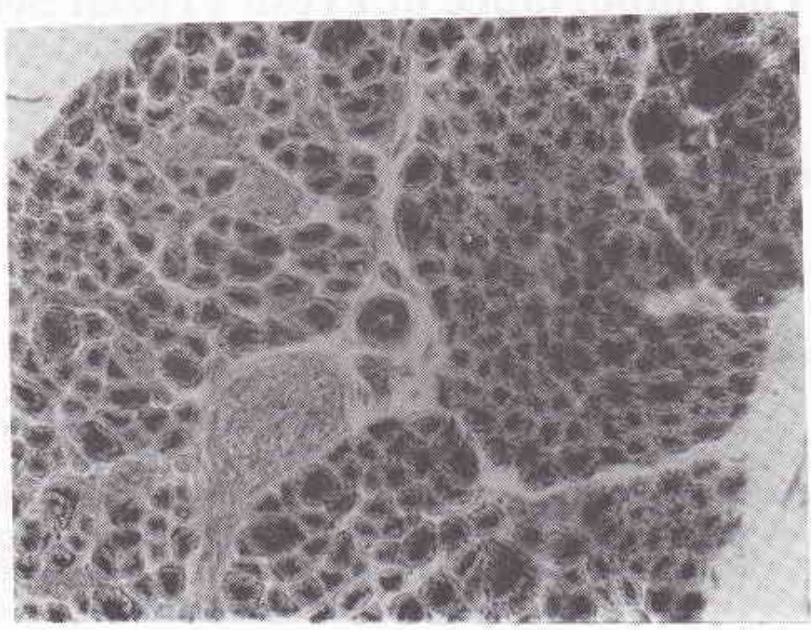

Figure 1. Myotubular myopathies, $H \& E$ staining, $40 x, H \& E=$ hematoxyclin \& eosin

H\&E than wih MGT, NADH, SDH (Fig. 2). RRF is a coarsely granular fiber, which stained bluish with $\mathrm{H} \& \mathrm{E}$ and red with the MGT. The RRF can easily be seen in fresh frozen section specimens, but very difficult to identify in the paraffin-embedded specimen. With conventional paraffin sections, it is difficult to detect mitochondrial disorders. Muscle biopsy enable us to diagnose mitochondrial myopathy, including mitochondrial encephalopathy, lactic acidosis and stroke-like episodes (MELAS), myoclonus epilepsy with ragged red fibers (MERRF) and chronic progressive external ophtalmoplegia (CPEO). In all of these diseases, we can identify the RRF, and/or SSV, and/or focal $\mathrm{CCO}$ deficiencies.

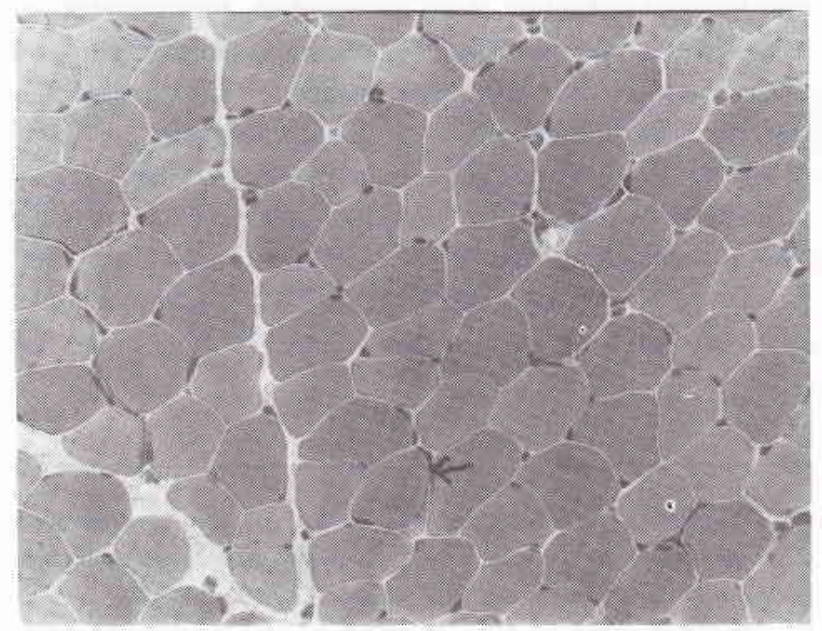

Figure $2 a . R R F, H \& E$ staining, $40 x, R R F=$ red ragged fibers, $H \& E=$ hematoxylin \& eosin 


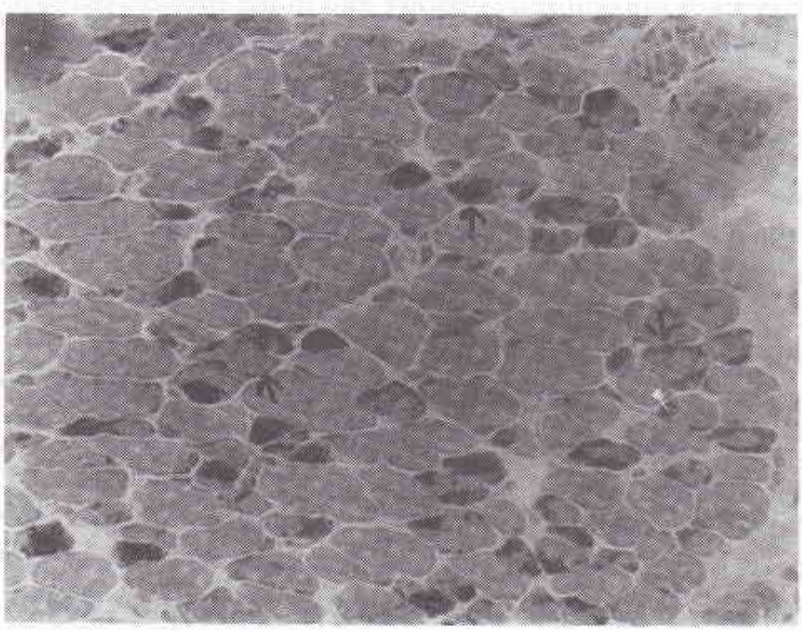

Figure $2 b . R R F, M G T$ staining, 40x, RRF = red ragged fibers, $M G T=$ modified Gomori trichrome

Modified Gomori trichrome is an important staining to identify some specific structure. With this staining we can see the myelinated fibers, nemaline bodies, cytoplamic bodies, tubular aggregates and mitochondria. Nemaline body myopathy can easily be diagnosed in fresh frozen sections, but difficult in paraffin sections after formalin fixation. Various congenital nonprogressive myopathies have been found since 1963, when Shy et al first described the nemaline myopathy. ${ }^{3}$ Before that time a number of muscular disorders in paraffin sections might be overlooked.

NADH-TR staining also helps us to detect myofibrillar organization and to classify muscle fibers. Almost all patients with pathological abnormalities may show structural disorganization with this staining. NADH is an oxydative enzyme in microsomes including mitochondria and sarcoplasmic reticulum. By means of NADH-TR staining, we can diagnose imprtant congenital myopathy known as central core disease, because the core region lacks mitochondria. The identification of the central core structure is important for anesthesiologist and surgeon, because patients with this autosomal dominant disease are highly susceptible for malignant hyperthermia. ${ }^{2,3,4,6}$ If we find this disease all family members of the patient must be carefully assessed.

SDH is a mitochondrial specific oxidative enzyme. ${ }^{1}$ An important finding, that occurs mostly in mitochondrial disorders is RRF; RRF can be highlighted in SDH staining; it provides an important clue for the diagnosis of mitochondrial myopathy. Another important pathological finding is the $\mathrm{SDH}$-reactive blood vessel in mitochondrial myopathies.
Also important is the lipid staining such as oil red O. The excess accumulation of lipid droplets in muscle fibers is demonstrated in mitochondrial myopathy and lipid storage myopathy. In paraffin embedded sections, we cannot detect the lipid in the specimen, because lipid is soluble in the alcohol, used either for embedding or for deparaffinization. If the lipid infiltrates the interstitium, we can still see the shape of the lipid cell. Because the accumulation of lipid droplets in muscle fibers is so tiny, we cannot identify it even in well fixed frozen sections.

Non specific esterase (NSE) may help to identify small angular fibers after denervation. The enzyme is elevated at the neuromuscular junctions and in lysosomes. Acid phosphatase is increased in degenerating and regenerating fibers especially in the former with active phagocytosis, becuase this enzyme is highly concentrated in lysosomes and in macrophages. Alkaline phosphatase is sometimes increased in early stage regenerating fibers.

Cytochrome C-oxydase, is an enzyme in mitochondrial electron transport system and its activity is demonstrated by histochemistry. In some patients with early onset of disease, this enzyme is completely absent leading to early death. In most of the patients with mitochondrial diseases, including CPEO, MERRF and MELAS, these enzyme deficient fibers are scattered throughout the whole body. The staining confirm the mitochondrial myopathy as well as the presence of RRF and SSV in the biopsy specimens. In a few cases the histopathological findings show a CCO focal deficiency without any RRF changes (Fig.3).

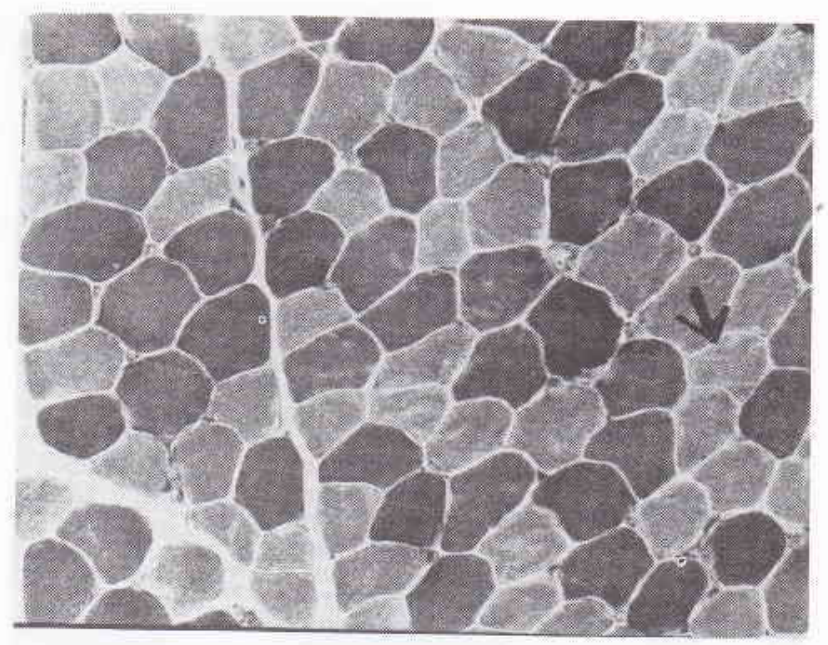

Figure 3. CCO focal deficiency, CCO staining, 40x, CCO = cytochrome C-oxydase 
ATPase provides us many information. To complete the staining, it takes at least 2 hours. We can differentiate the fiber type into type $1,2 \mathrm{~A}, 2 \mathrm{~b}$ and $2 \mathrm{C}$ fibers (fig.4). In normal human muscles, type 1, 2A, and 2B fibers are almost equally distributed in a mosaic pattern, so a disturbed mosaic pattern is a pathognonomic finding of a neurogenic process. There is a reciprocal relationship between phosphorylase and the oxydative enzymes. In general, type 1 and 2 fibers are recognized by the different concentration of ATPase, phosphorylase, and the other oxydative enzymes. However, in some fibers this quantitative differentiation is unclear. ${ }^{1}$

Other stainings which may provide us some diagnostic clues are phosphofructokinase and menadione linked alpha-glycerophosphate dehydrogenase.

\section{IMMUNOHISTOCHEMISTRY}

Fresh frozen tissue is also applicable for immunohistochemistry to detect specific protein defects which play important roles in the pathogenesis of diseases, while it is not traceble from paraffin embedded tissue.

It is not always easy to make a diagnosis of muscular dystrophy, from clinical and morphological findings; for instance, diagnosing limb girdle muscular dystrophy and mani-festing carriers of Duchenne muscular dystrophy (DMD) by clinical and histopathological findings alone. ${ }^{7,8}$ To differentiate the disease, an immunohistochemical staining by using antidystrophin antibody gives a lot of help. Dystrophin is a protein product of the gene, ${ }^{9}$ and is almost completely absent in the sarcolemma in DMD muscles, minimal to patchy

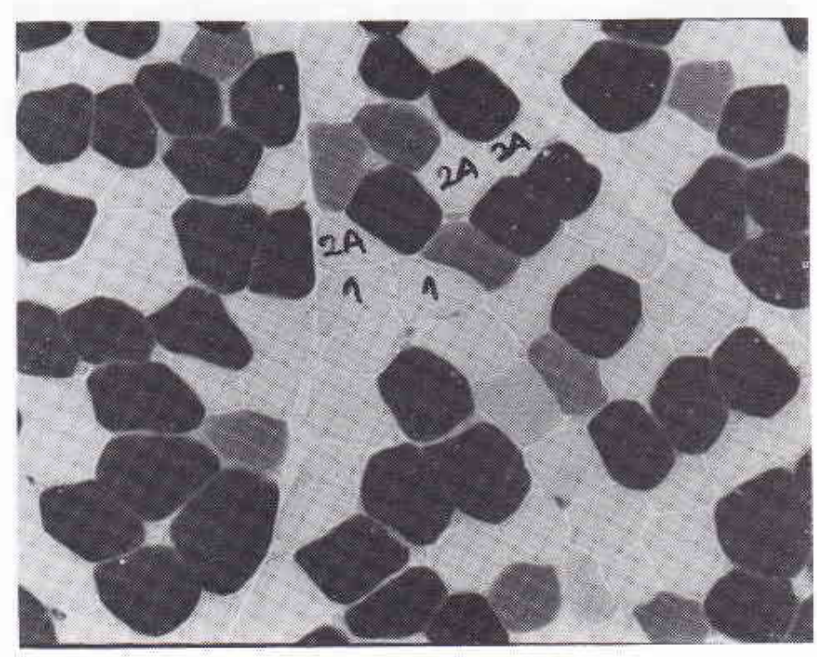

in Becker muscular dystrophy and in the mosaic pattern of manifesting DMD carrier. In other progressive muscular dystro-phies the dystrophin is positively present. $^{2,10,11}$

McDonald ${ }^{12}$ reported a case whose EMG showed neurological changes, but histopathological findings suggested a myopathic process. Dystrophin staining helped to make the final diagnosis. Even in a myopathic process, the biopsy may show a neurogenic pattern for several reason. First, segmental degeneration of indivi-dual muscle fibers might be followed by segmental re- innervation (myopathic reinnervation). ${ }^{13}$ Secondly, in chronic myopathies, splitting of muscle fibers may give the false appearance of a group atrophy. ${ }^{14}$ Conversely, myopathic histological patterns may be seen in chronically denervated muscles. ${ }^{15}$ Conflicting EMG and biopsy results have been described in some genetic neuromuscular disorders including Emery-Dreyfuss muscular dystrophy, limb girdle muscular dystrophy, Charcot-Marie-Tooth syndrome and spinal muscular atrophy. ${ }^{13}$

Another importance of dystrophin staining is, it can determine certain types of muscular dystrophies as proposed by the workshop sponsored by the European Muscular Centre. There main muscular dystrophies can be diagnosed by the dystrophin staining, namely Duchenne muscular dystrophy, Becker muscular dystrophy and the ruling out of limb girdle muscular dystrophy. 10,11

The advantages in muscular dystrophy diagnosis is based on the discovery of structure and function of the dystrophin associated glycoprotein(DAG). Dystrophin is associated with a large oligomeric complex of

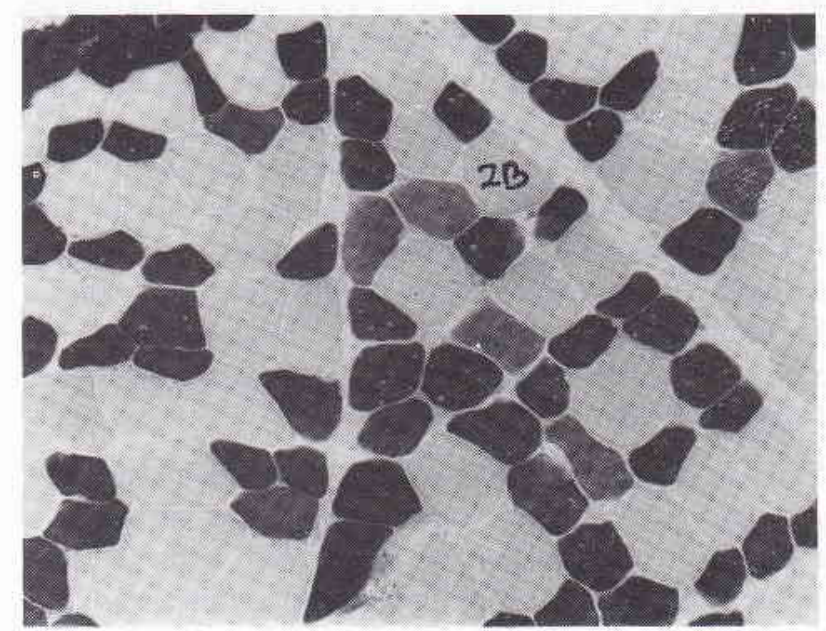

Figure 4. Muscle fiber typing, ATPase staining, 40x, ATP ase = adenosin triphosphatase 
sarcolemmal proteins, comprised of a 156-kd glycoprotein (156DAG), a 43-kd protein (43DAP), a 50-kd glycoprotein (50DAG), a 35-kd glycoprotein (35DAG) and a $25-\mathrm{kd}$ protein (25 DAP). ${ }^{16}$ The abnormalities of 50DAG, for example, is pathognonomic for the severe childhood autosomal recessive muscular dystrophy (SCARMD). ${ }^{17}$ This disease is highly prevalent in North Africa, but also reported in other countries. The overall clinical symptoms mimic DMD. Without immunohistochemical staining on the sporadic patient it may be difficult to obtain a definite diagnosis.

The discovery of utrophin has stimulated us to reconsider the treatment of DMD. If the secretion of utrophin could be increased by a genetic or pharmacological manipulation, it could be beneficial for the prevention of muscle degeneration. ${ }^{16}$

\section{THE ADVANTAGES OF FRESH FROZEN SEC- TION ON MUSCLE BIOPSY}

As mentioned above, there are many advantages, beginning from an accurate diagnosis to the pathophysiology of muscle diseases by performing a muscle biopsy in fresh frozen sections. It is not difficult and easy to handle. The cooperation between the clinician and the pathologist is necessary to promote the procedure. Without clinical and laboratory data, it is hard to make a pathological diagnosis. Some special skill is necessary to perform the biopsy in order to obtain enough samples for pathological examinations. The most important thing is how to process the muscle biopsy specimens for histochemical examination.

One of the advantages of fresh frozen sections is that the clinician will get a tentative answer within 2 hours after the muscle biopsy. After fixation we cut the frozen section with a cryostat and then perform the 3 most important stainings, H\&E, MGT and NADH, $\mathrm{SDH}$ and $\mathrm{CCO}$. The staining can be finished in 60 minutes. The final pathological diagnosis will be given after routine histochemical and immunohistochemical stainings, usualy 2-7 days after the muscle biopsy. If it is an urgent case, all the histochemical stainings can be done on the same day. If there is still enough tissue, one can make formalin fixed and paraffin embedded sections which may help to identify infiltrated cells in more details. For routine examinations, formalin fixation can be ommited.

The important stainings in Indonesia are H\&E, MGT, $\mathrm{NADH}, \mathrm{SDH}, \mathrm{CCO}$ and ATPase. From these six stainings, we can obtain approximately $99 \%$ of definite pathological diagnoses. Other stainings to be considered in Indonesia are PAS, oil-red-O, NSE, and the phosphatases. Stainings like PFK, phosphorylase, AMP deaminase are only exceptionally necessary, maybe once or twice a year.

As described above, it's time to introduce the fresh frozen section technique for muscle biopsy in Indonesia. Many abnormal findings can be highlighted by histochemical stainings using the fresh frozen sections. We will get more appropriate diagnoses and thus better treatment and follow up of the patient. Research work would be stimulated and cooperation with the Eyckman Institute involving mitochondrial diseases could be started. However, if we still depend on conventional paraffin-embedded sections, we will stay behind and miss many important findings.

A comparative study on muscle biopsy between formalin and paraffin embedded sections and fresh frozen specimens has proven the superiority of the latter.

\section{ACKNOWLEDGEMENT}

Dr. Rino Pattiata holds the Monbusho scholarship from the Government of Japan to work in the ICMR laboratory, Kobe University School of Medicine.

\section{REFERENCES}

1. Dubowitz V. Muscle Biopsy. 2nd Ed. London: Baillere Tindall, 1985

2. Nonaka I. Muscle biopsy for clinicians (in Japanese). Tokyo: Nihoniji-shinpo, 1994

3. Shy GM, Engel WK, Somers JE, Wanko T. Nemaline myopathy: a new congenital myopathy. Brain 1963;86:799810

4. Bodenstein JM. Congenital myopathies. Muscle Nerve 1994; 17:131-44.

5. Arikawa E, Hoffman EP, Kaido M, Nonaka I, Sugita H, Arahata K. The frequency of patients with dystrophin abnormalities in a limb-girdle population. Neurology 1991;41:1491-6.

6. Middleton L, Moser H. Rare neuromuscular disease. In: Emery AEH, editor. Diagnostic criteria for neuromuscular disorders. Baarn: European Neuromuscular Centre, 1994:913

7. Hoffman EP, Kunkel LM, Angelini C, Clarcke A, Johnson $\mathrm{M}$, Harris JE. Improved diagnosis of Becker muscular dystrophy: dystrophin testing. Neurology 1989;39:1011-7

8. Norman P, Coackley J, Thomas N, Harper. Distinction of Becker from limb-girdle muscular dystrophy by means of dystrophin cDNA probes. Lancet 1989;1:466-8.

9.Hoffman EP, Brown RH, Kunkel LM. Dystrophin: the protein product of the Duchenne muscular dystrophy locus. Cell 1987:51:919-28. 
10. Jennekens FGI, ten Kate LP, de Visser M, Wintzen AR. Duchenne and Becker muscular dystrophy. In: Emery AEN, editor. Diagnostic criteria for Neuromuscular disorders. Baarn: European Neuromuscular Centre, 1994: 9-13.

11. Bushby KM. Limb girdle muscular dystrophy. In: Emery AEN. editor. Diagnostic criteria for Neuromuscular disorders. Baarn: European Neuromuscular Centre, 1994: 25-31.

12. McDonald TD, Medori R, Younger DS, Chang HW, Mineti C, Uncini et al. Becker dystrophy of spinal muscular atrophy -dystrophin studies resolve conflicting results of electromyography and muscle biopsy. Neuromusc Dis $1991 ; 1: 195-200$
13. Hernriksason KG, Stalberg E. The terminal innervation pattern in polymyositis: a histochemical and SFEMG study. Muscle Nerve 1978;1:3-12.

14. Bradley WG, Jones MZ, Mussini JM, Fawcett PR. Beckertype muscular dystrophy. Muscle Nerve 1978;1:111-32.

15. Achan AN, Anderson MS. Myopathic changes in amyotrophic lateral sclerosis. Neurology 1974;24:477-88.

16. Matsumura K, Campbell KA. Dystrophin-glycoprotein complex: its role in the molecular pathogenesis of muscular dystrophies. Muscle Nerve 1994;17:2-15.

17. Matsumura K, Tome FMS, Collin H, Azibi K, Chaunch M, Kaplan JC. 50kd dystrophin-associated glycoprotein in severe childohood autosomal ressesive muscular dystrophy. Nature 1992;359:320-2. 